\title{
Sharing country food: connecting health, food security and cultural continuity in Chesterfield Inlet, Nunavut
}

\author{
Sarah L. Newell, 1 (1) Nancy C. Doubleday ${ }^{2}$ (1) \& Community of Chesterfield Inlet, Nunavut \\ ${ }^{1}$ Faculty of Health Sciences, McMaster University, Hamilton, Canada; \\ ${ }^{2}$ Faculty of Humanities, McMaster University, Hamilton, Canada
}

\begin{abstract}
Food security is a complex topic defined not just by having enough nutritious food to eat but also by cost, safety and cultural considerations. In Arctic Inuit communities, food security is intimately connected to culture through traditional methods of harvesting country food. In Chesterfield Inlet, Nunavut, community-based research was conducted in collaboration with Chesterfield Inlet community members using interviews and community engagement. Community members were consulted about the design of the interview guide, recruitment of participants, analysis and validation of results. This study aims to develop a theoretical framework of how food security, cultural continuity and community health and well-being are interconnected to allow for a richer understanding of how increased shipping, climate change and social changes are impacting community members. In Chesterfield Inlet, harvesting and consuming country food (e.g., seal) is perceived as the mechanism that connects food, culture and community health. Sharing of freshly harvested country food supports the food security of community members without hunters in their families, aligns with hunters' cultural beliefs and promotes community health and well-being. Changes that reduce a hunter's success in harvesting country food limit her or his ability to share country food, which negatively impacts community health and well-being. The results of this study support existing community efforts to adapt to changes that impact harvesting success.
\end{abstract}

\section{Keywords}

Inuit; culture; traditional knowledge; climate change; Chesterfield Inlet; health and well-being

\section{Correspondence}

Sarah L. Newell, 60 University Private, Ottawa, ON K1N 8Z4, Canada. E-mail: newells@mcmaster.ca

\section{Introduction}

Food security has been the focus of much research in the Canadian Arctic in an effort to understand and address the high rates of food insecurity among Indigenous peoples in some regions. Inuit cultural continuity and community health and well-being have also been subjects of study; however, a gap exists in terms of connecting these concepts. This paper seeks to answer the research question: from the perspective of Inuit living in Chesterfield Inlet, what mechanism links food security, cultural continuity and health and well-being at a community level?

Community-based research methods were used to derive this research question, and data were gathered through interviews conducted with elders and hunters and at community meetings. All community members were welcomed to participate, and different individuals were involved in each phase of the research. This paper demonstrates how sharing and consuming country food emerged as the mechanism connecting food security, cultural continuity and community health and well-being from the perspective of Inuit living in Chesterfield Inlet.

\section{Literature review}

\section{Food security}

Food security is complex and dynamic and its definition has evolved over the years. The most comprehensive understanding of food security is continuously having enough safe, healthful food, at an affordable cost, to meet nutritional and caloric needs and the preferences of the individual or household (Pinstrup-Andersen 2009). This broad understanding is pertinent to this study as it includes important factors, such as cost and preference, which allow us to understand and address the complexity of food security in the Arctic. Food insecurity rates in Nunavut are the highest of any Indigenous population in a developed country, with $70 \%$ of households being 
affected in 2008 (Council of Canadian Academies 2014; Cormier 2016). Past research has focused on defining food insecurity, assessing its prevalence and examining the key factors that lead to such high rates amongst Inuit in Nunavut. Factors impacting food insecurity in previous research include the nutrition transition away from country food due to contaminant concerns, increasing consumption of market foods with increasing availability in stores alongside decreasing access to country food, changes in family composition and rising costs of gas and hunting equipment; some research has investigated the potential for a country food market to address some of these concerns (Thompson 2005; Chan et al. 2006; Donaldson et al. 2010; Ford et al. 2010; Berrang-Ford et al. 2011; Council of Canadian Academies 2014; Guo et al. 2015; Ford et al. 2016; Ready 2016, 2018a; Searles 2016; Gmelch et al. 2017). "Country food" is the term Inuit use for foods harvested locally, such as caribou, seal, berries and eggs. This study focuses on the marine mammal component of country foods. Previous studies have focused on food systems, biomedical impacts of contaminant exposure, nutrient intake and the prevalence of food insecurity and, more recently, the implications of climate change for Inuit food systems (Donaldson et al. 2010; Ford et al. 2010; Berrang-Ford et al. 201 1; Egeland, Williamson-Bathory et al. 2011; Ford \& Beaumier 2011; Council of Canadian Academies 2014). Beyond food security concerns, the physical act of harvesting country food is tied to cultural continuity-the continuation of traditional culture-which is intimately tied to health for Inuit (Kirmayer et al. 2000; Reading \& Wein 2009; TRC 2015; Hackett et al. 2016; Newell et al. 2019). Previous research provides an important baseline upon which to demonstrate Inuit perspectives about how changes are impacting community health and well-being in the Canadian Arctic. Food security is part of a larger, complex system, which needs to be understood at a community level in order to determine potential policies and strategies that build on the strengths of each community and create opportunities to adapt and thrive.

\section{Cultural continuity}

When it comes to Indigenous health in Canada, there are many different ways in which colonial policies and cultural change have impacted health outcomes. The Indian Residential School system and the policies surrounding this system strove to eliminate Indigenous culture and assimilate Indigenous peoples into Canadian society (Kirmayer et al. 2000; TRC 2015), causing intergenerational health impacts of such trauma (Hackett et al. 2016). Cultural continuity-defined here as the continuation of traditional culture within modern society (Oster et al. 2014) -is an additional determinant of health and well-being for Indigenous peoples across North America (Chandler \& Lalonde 1998; King 2009; Auger 2016). Efforts to retain and build culture, such as continuing to harvest and consume country food, at the level of both individuals and communities greatly impact the health of Indigenous peoples (Kirmayer et al. 2000; Newell et al. 2019).

\section{Community health and well-being}

There is a growing recognition that the collective nature and approach to life of Inuit communities means that individual health and well-being cannot be separated from the context within which they live (Wiseman 8 Brasher 2008; Kral \& Idlout 2012; La Placa et al. 2013). The definition of community well-being has changed over time and varies across different disciplines (Wiseman \& Brasher 2008; Parlee \& Furgal 2012; La Placa et al. 2013); here, we define it as "the combination of social, economic, environmental, cultural, and political conditions identified by individuals and their communities as essential for them to flourish and fulfil their potential" (Wiseman \& Brasher 2008). Factors involved in measuring or understanding community well-being include housing, intergenerational and interpersonal relationships within and between families, access to economic and social resources, the state of ecology and the environment, physical safety and social cohesion (La Placa et al. 2013).

Inuit communities in the Canadian Arctic are traditionally family-based and practice a collectivist culture with important intergenerational relationships that have been disrupted in recent years (Kral \& Idlout 2012). Within Inuit communities, community well-being is supported by intergenerational transfer of Inuit Qaujimajatuqangit, or Inuit traditional knowledge (Kral \& Idlout 2012), which represents an important link connecting cultural continuity and community health and well-being with the health of the environment (Parlee $\&$ Furgal 2012). Inuit Qaujimajatuqangit or Inuit traditional knowledge encompasses knowledge about survival on the land and harvesting practices, as well as Inuit values and a way of life that includes both general knowledge to the Arctic and knowledge specific to each community. Within this context, the community lens needs to be used to understand how health and well-being are related to food security and culture.

\section{Connecting food, culture and well-being}

While Inuit food systems are now mixed, country food has been identified as a way to support the food security 
amongst Inuit in the Canadian Arctic. Traditional harvesting of country food is intimately tied to Inuit identity and cultural continuity (Weihs et al. 1993; Lardeau et al. 2011; Harder \& Wenzel 2012; Collings et al. 2015; Ready 2016, 2018a, b; Searles 2016). Sharing country food is part of Inuit traditional knowledge, varying with social networks and underlying sharing practices (Lardeau et al. 2011; Collings et al. 2015; Ready 2018b), as well as resource type (Harder \& Wenzel 2012). Each community's harvesting and sharing practices surrounding country food are informed by unique combinations of Inuit traditional knowledge, culture and a growing market for freshly harvested country foods; choices between consuming country foods versus market food are additionally complicated by awareness and concern regarding contaminants bioaccumulating in large marine mammals (Weihs et al. 1993; Paci et al. 2004). Previous studies have demonstrated how harvesting, sharing and consuming country food is part of Inuit culture. They have investigated how Inuit food security is tied to sharing and consuming country food. Finally, they have shown how cultural continuity in the form of continuing to harvest, share and consume country food is linked to individual health and well-being. However, few studies have explored the connections among all three concepts. Once we understand how food security, cultural continuity and community health and well-being are connected, we can understand how community health and well-being is impacted by changing patterns of country food harvesting and consumption. This paper seeks to address the mechanism that links food security, cultural continuity and health and well-being at a community level in Chesterfield Inlet. Figure 1 graphically represents the general theory based on Newell's analysis of the literature, which was explored in collaboration with community members

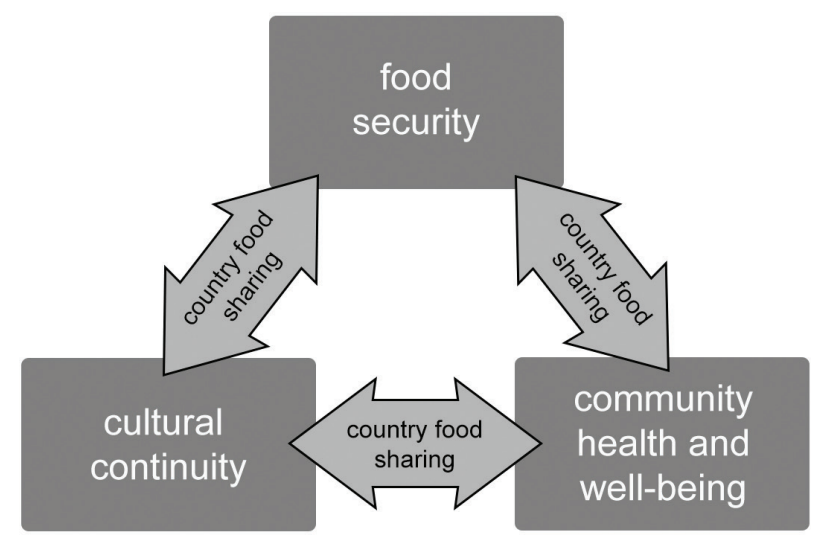

Fig. 1 Theoretical model representing how food security, cultural continuity and community health and well-being are linked through the sharing of country food. of Chesterfield Inlet, through a series of interviews and community consultations.

The Arctic is experiencing some of the most pronounced environmental changes associated with climate change, including temperature increases greater than in other regions of the world (Masson-Delmotte et al. 2018). Indigenous peoples living in the Arctic are recognized to be at increased risk (Masson-Delmotte et al. 2018). Inuit across the Canadian Arctic have been observing changes in plants and wildlife (Ford et al. 2007; Nancarrow \& Chan 2010; Downing \& Cuerrier 2011; Rosol et al. 2016). These changes are having negative impacts on the harvesting and consumption of country food, thereby increasing food security concerns (White et al. 2007; Nancarrow \& Chan 2010; Wesche \& Chan 2010; Rosol et al. 2016). Following from their culture of connectedness to the land, Inuit have also expressed feelings of loss stemming from their observations of climate change and have described the negative health impacts of climate change (Cunsolo Willox 2012; Cunsolo Willox et al. 2014). The research reported here shows how mechanisms of sharing country food can shed light on the impacts of climate and shipping changes on Inuit health.

\section{Methods}

\section{Study area}

Chesterfield Inlet is a community located on the west coast of Hudson Bay, at the mouth of Chesterfield Inlet, the waterway that leads to the nearby community of Baker Lake. Chesterfield Inlet has 415 inhabitants, 94\% of whom are Inuit (Statistics Canada 2016). Traditional activities such as hunting, fishing and passing on Inuit traditional knowledge about survival on the land are still frequently practiced and are important in Chesterfield Inlet.

The waterway is used to transport supplies to the neighbouring Meadowbank mine outside Baker Lake, which is an important community concern (CBC News 2015). Large ships travel across Hudson's Bay to dock in the harbour at Chesterfield Inlet, where they spend a week offloading cargo onto a smaller ship that can deliver the supplies along the Chesterfield Inlet river to the mine. Whereas the Chesterfield Inlet harbour once teemed with a variety of seals and whales, inhabitants of the community have observed that marine mammals now avoid the area and they attribute this to the presence of ships (CBC News 2015).

\section{Community-based research}

The community of Chesterfield Inlet engaged in designing the research question, determining appropriate 
participants, member-checking, discussing the results and deciding the knowledge translation and research outputs. The community-based approach to this research is informed by the spirit of the guidance found in Chapter 9 of the Tri-council policy statement on research involving First Nations, Métis and Inuit peoples of Canada (CIHR 2010). This community-based study involved two methods of data collection: semi-structured interviews and community meetings consulting the community, both using the same interview guide approved by both the McMaster Research Ethics Board (protocol number 2016 158) and the Nunavut Research Institute (license number 03017 17N-M). Interviews were audio-recorded unless participants preferred not to be recorded, and written notes were taken for all interviews and community consultations. An informed consent was obtained from all participants included in the study and an additional informed consent was also obtained for those participants identified in this article.

There were four phases of the research to ensure the community was engaged throughout the process and all community members were invited to be part of each phase. These phases included identifying a common research objective, collecting data, reviewing preliminary results and sharing final results with the community members. This research was guided by a Community Partner who grew up in the community, works and lives there, functioned as a partner to guide the research and provide access to participants. The sampling approach, informed by the Community Partner, used strategic and snowball sampling, beginning with elders and any other interested members. In the initial strategic sampling, we reached out to elders first, to establish a baseline understanding and to note changes; we then used a snowball approach by asking participants to suggest other people we should talk to in the community to get a better understanding.

In phase 1 (Table 1), Newell proposed collaborating on research about how food security, cultural continuity and community health and well-being are connected in the context of climate changes. The impact that the significant increase in shipping to the nearby mine was having on marine mammals emerged as an important focus for the research. Community members expressed frustration that at prior meetings and consultations, they had voiced concerns but these had fallen on deaf ears. A framework to understand how various changes in the Arctic impact human health was proposed. This framework would support the community's desire to advocate for changes that will support food security and community health and well-being.

During phase 2 (Table 1), the Community Partner accompanied Newell for each interview and was present during all community meetings. During interviews, the Community Partner translated between English and Inuktitut, in accordance with the participant's preferred language for the entire interview or specific questions. He also helped guide the interviews and would often ask follow-up questions to elicit deeper responses from participants. Interviews took place wherever participants were most comfortable their workplace, the hamlet office or, most often, their homes. At home-based interviews, other family members were often present, including partners, children or friends who were not formal participants but who contributed by agreeing with the respondents' remarks.

Data were collected through 27 community member interviews and a community consultation attended by nine community members. Participants included male and female elders, current hunters and youth participants. Additional community stakeholders chose to engage in different phases of the research process based on their interest and availability. Interviews ranged from 10 minutes for those fluent in English to 1.5 hour for those participating in Inuktitut, with the average interview being one hour in length. The community consultation was two hours in length with Inuktitut translation occurring throughout.

Table 1 Phases of the study.

\begin{tabular}{|c|c|c|}
\hline Phase & Description & No. of participants \\
\hline (1) Community consultation & $\begin{array}{l}\text { Open-house community consultation and conversations with } \\
\text { elders, community representatives of businesses, } \\
\text { representatives of organizations and government employees }\end{array}$ & 20 \\
\hline (2) Data collection & $\begin{array}{l}\text { Open-house meeting where all community members were } \\
\text { welcome to participate, followed by interviews with elders and } \\
\text { current hunters }\end{array}$ & Open-house meeting: 9, interviews: 27 \\
\hline (3) Results consultation & $\begin{array}{l}\text { Open-house consultation and one-on-one conversations with } \\
\text { participants }\end{array}$ & $\begin{array}{l}\text { Open-house consultation: } 12 \text {; one-on-one } \\
\text { conversations: } 25+\end{array}$ \\
\hline (4) Share final results & $\begin{array}{l}\text { Presentation of posters with English and Inuktitut results and } \\
\text { photographs of community members }\end{array}$ & $\begin{array}{l}\text { All participants, Hamlet council, Hunters and } \\
\text { Trappers Organization, etc. }\end{array}$ \\
\hline
\end{tabular}


During all phases of the research (Table 1), posters were distributed throughout the community, inviting people to participate. Many community members also participated informally throughout the research phases by sharing their observations of climate change, the impact of shipping on marine mammals and the importance of sharing country food within the community, confirming interview results.

\section{Analysis}

The recordings were transcribed verbatim by Newell and analysed thematically using the framework in Fig. 1 to guide the process of deductive coding followed by inductive coding. This approach was congruent with our objective to capture the view of Inuit living in the community without emphasizing or imposing theoretical concepts over community voices. Next, the data were charted into the theoretical framework (Gale et al. 2013); this charting allowed for comparison of a single code across the different interviews and community consultations. Phase 3 (Table l) served as member-checking of the preliminary results to ensure accurate representation of their views and to provide an additional opportunity for community members to engage in the research. A brief report that summarized the key findings was made available to the community for early consideration and advocacy work (Newell 2017).

When the interviews were conducted, participants could indicate whether they wanted to remain anonymous or share their names; when the results were returned to the community, this was confirmed, with special attention paid to quotations that identified individual participants. While age data were not collected for participants and if a participant self-identified as an "elder," this was indicated beside his or her quotation; "current hunters" were those who identified as hunters but not as elders (often between mid-20s and late 50s) and "community members" were those who participated but did not identify as hunters.

\section{Results}

Harvesting and sharing country food emerged as the two key mechanisms that link food security, cultural continuity and community health and well-being in Chesterfield Inlet. Participants expressed the desire to consume as much country food as available with various limiting factors. Participants described continuing the practices of harvesting and sharing country foods as being an important part of Inuit traditional knowledge and good for individual and community health and well-being. Additionally, participants recognized the impact that shipping and climate change has on these links (Newell 2018).

\section{"If we could have it every day, we would": eating country food and food security}

Country food is an essential part of food security for elders and current hunters in Chesterfield Inlet. Amongst participants in Chesterfield Inlet, they reported that 50\% or more of their meals included country food, specifying that country food was often lunches and dinners, not a breakfast food. Most participants said that they would eat country food as often as it was available, being limited only by access and health issues.

[I don't eat country food] lately because of my health...I can't really ingest caribou or can't eat caribou meat. I eat lots of fish. (Community elder, female)

After her kidney transplant, she has to [be] very careful what she eats. So, she [is] cautious today not to eat like any [raw] country food... Whenever there's country food she eats it ... [cooked for] lunch, afternoon or supper. (Translator paraphrasing words of a community elder, female)

These views and practices align with the Nunavut food guide (Dept. of Health 2020) and related policies promoting country food consumption (Davidson et al. 2012; Wakegijig et al. 2013; Ford et al. 2016). However, participants recognized that preferences might vary across the community, with the younger generation having a preference for more store-bought food. Country food is socially and culturally significant to Inuit as it is a staple food source that relies on access to the land and the ability to travel on the land. Elders said they were eating less country food than they did during their childhoods for a number of reasons, including more access to storebought food and less access to country foods due to the loss of key family members responsible for accessing it.

She doesn't eat any more seal because when her husband passed away...there seems to be less seal meat on the table. (Translator paraphrasing words of a community elder, female)

Mainly country food was fed to us growing up 'cause my parents were from the older generations. They hardly had any store-bought foods so we [ate] a lot of country food then. (Harry Aggark, current hunter, male)

I ate a lot more country food when I was younger. (Current hunter, male)

\section{"Family looks out for one another": sharing country food and food security}

Many of the participants were still able to go out on the land to harvest country food and ate a lot of what they harvested themselves. Some participants explained that the loss of a 
family member who used to take them out on the land or lack of equipment limited their ability to harvest their own country food. As a result, they relied on others within the community to share through informal or formal mechanisms, such as the Community Hunt Program offered by the Department of Economic Development and Transportation. Those hunters with surplus would share with community members who did not have access to country food, such as elders, single mothers and those without equipment. Sharing country food is a traditional cultural practice that participants described as an important way to support food security within the community.

Right now, especially when I'm budgeting money, I always make sure I have country food. (Community member, female)

If a family goes through radio like... asking if anybody got some caribou, they'll get some hunters to go out and they'll give you some caribou meat [for] the whole community. (Community elder, female)

Some of it [country food he eats] is coming from him, he harvests his own. But when it gets too cold his son also hunts for him. (Translator paraphrasing words of a community elder, male)

Family looks out for each other so with traditional food you spend less money on groceries. (Current hunter, male)

Sharing country food is also seen as being an important part of helping to support community members financially. While equipment to hunt and fish is expensive, there are programmes to offset the costs, such as the Hunter Food Distribution Program, which provides funding for community harvesting or equipment for harvesters. Those hunters with equipment see harvesting country food as the only way to afford to live in the Arctic, given the high costs of store-bought food.

\section{Harvesting and sharing country food as a source of cultural continuity}

According to community members in Chesterfield Inlet, Inuit traditional knowledge is the large, unwritten laws about the environment that cannot be elucidated or codified, including ideas about conservation, survival on the land, changes that have occurred over an elder's lifetime and how to live one's life in accordance with traditional values. Having access to elders and Inuit traditional knowledge is one of the reasons participants remained in this community rather than moving elsewhere.

Oh yeah, [having elders in the community] it's very important, they're our wisdom. They're our computer for the sea, out in the land, they're our computer.
(Community member, female)

There were two parts of Inuit knowledge and culture that emerged as being very important to participants in Chesterfield Inlet: (1) continuing to harvest country food while passing on these techniques to the younger generation and (2) sharing country food within the community. Learning and passing on Inuit traditional knowledge about harvesting practices is often done on the land; people learn as they engage in traditional hunting and fishing activities. Passing on Inuit traditional knowledge and continuing these cultural practices are important parts of Inuit life throughout the Canadian Arctic that are being affected by climate change (Downing \& Cuerrier 2011; Kendrick 2013; Ford et al. 2014). Families often go out on the land after work or for family vacations as a way to carry on some of the traditional nomadic ways of life, despite living in permanently settled communities now. It is on these trips that people learn through watching their family, friends, elders and other community memberswhoever is going out at the time.

All the hunting skills I learn are passed down from my dad ...Practically every time he would go out boating I would tag along, I wouldn't be left behind [laughs]. (Harry Aggark, current hunter, male)

We have to give them advice before we pass away ourselves... I like passing my knowledge, what I learned so they will remember me when I'm gone [laughs]. (Casimir A.M. Kriterdluk, community elder, male)

[Teaching my five-year-old son to harvest country food is important because] He could pass it down to his kids too when he has kids. (Current hunter, male)

Along with harvesting and consuming country food, sharing country food within the community is an important part of cultural continuity, as described by participants. Participants and other community members passionately articulated how sharing country food rather than selling it is an important part of their culture that has been passed down for generations. This is a cultural practice that the elders felt it is important to maintain.

They just love hunting, that's their tradition. They just go out hunting and they share it. They don't request to get paid or get gas or anything for it. (Community member at the community meeting, female; others agreed with this statement)

They always share their, whatever they caught to older people first. Especially the hunters, yeah... Always share their hunt or whatever they caught. Especially my relatives now. They are mostly my relatives in Chester. (Casimir A.M. Kriterdluk, community elder, male) 
He just mentioned that they want to keep the tradition like country food that's just been harvested, they share with the community or they can announce that anybody can come and pick up freshly caught country food. 'Cause they want to keep their tradition alive, back then whatever's been harvested they would share it with the people, not sell it, they prefer to not sell it. (Translator paraphrasing words of a community elder, male)

\section{"It's a refresher for our mind, body and soul": harvesting and sharing country food supports community health and well-being}

Harvesting country food and continuing to pass on Inuit traditional knowledge is an important part of survival in the Canadian Arctic, is part of Inuit identity, "keeps you grounded" (in the words of community members), is good exercise and is something people love to do. Harvesting country food promotes a hunter's health not just through increased physical activity and food security but also improved mental health.

[People] can't just ... stick in town ... for us when we go out on the land it's a refresher for our mind, body and soul. It just refresh, get some fresh air away from town, just enjoy the scenery, enjoy the land. (Current hunter, male)

As this hunter conveyed, time spent going out on the land, whether for harvesting activities or just to observe seasonal changes, has an important impact on individual health and well-being, as seen across the Canadian Arctic (Downing \& Cuerrier 2011; Kendrick 2013; Ford et al. 2014). Through living in the community, Newell observed this phenomenon of going out on the land daily in the spring to observe the changes in snowmelt during the periods of 24-hour sunlight. Many participants described how time spent on the land improved their mental health and supported their individual well-being, independent of whether country food was harvested during the process.

Sharing country food is also seen as larger than just a cultural practice or a way to support an elder's food security. Participants often emphasized that sharing freshly harvested country food gives this small community a good feeling, makes people feel welcome, connects people, supports the health of the community and is an important strength of Chesterfield Inlet.

First of all, ...when people are selling country food or harvested food ... it's not nice 'cause they don't agree with it because it's not part of their livelihood growing up. Because if some people are selling country food or harvested food, some members in the community won't afford it because they don't have money or revenue on their table or to support their family members. So elders would not support that, selling harvested or freshly caught country food in the community. (Translator paraphrasing words of Eli Kimmaliardjuk, community elder, male)

When you don't sell country food harvested it makes it more welcome in the community or family member, ...it shows more respect, less hostility, you know... their tradition is generally [country food] given at no cost. (Translator paraphrasing words of community elder, male)

Better connected yes. But overall, she doesn't know how other people think in the community, but her opinion [is that] it does create better connections with members in the community, sharing country food. (Translator paraphrasing words of community elder, female)

Yes [sharing country food is] good for the health and mind you know...And for the community, yes. (Community elder, male, spoken through a translator)

The support for continuing this cultural practice by the Department of Economic Development and Transportation represents a unique food policy for Nunavut, which is explored in more detail below in the policy implication section.

\section{How changes impact this framework}

Harvesting and sharing country food is seen as important practices to continue, but ones that are being threatened by changes occurring in the Arctic. These include climate, shipping and social changes, which are simultaneously impacting participants and the community more broadly. Participants have observed many climate changes, the most relevant being changes in sea-ice thickness, snow quality and timing of sea-ice freeze and break-up. This has limited the time when it is safe to harvest using seaice routes and has increased concerns about the safety of hunters travelling on sea ice, concern about the effectiveness of survival techniques, such as building snow shelters. Occurring alongside these climate changes are social changes. Participants were concerned that the younger generations are not going out on the land to learn harvesting techniques as often, they do not value traditional knowledge about survival on the land because they think they are invincible, they do not listen to their parents or grandparents and they are losing their language because technology today uses English rather than Inuktitut.

They [young people] don't visit their parents anymore. They think they could survive themselves, no way! They have to help one another, that's the only answer in this world. You do have to think about the other 
people too, eh. You can't live alone. (Casimir A.M. Kriterdluk, community elder, male)

[Harvesting country food is] part of their tradition you know, individual hunters ... they wait until the ice gets thick [before] they would go floe edge, you know, they wouldn't just travel when the ice is too thin. Depends generation to generation but you know, knowledge. Based on thickness or thinness of the ice they would travel or not. If it's thick they go floe edge if it's too thin they wouldn't travel, it's like weather patterns. Yeah [it's important for people to pass on knowledge about] the conditions of ice. (Translator paraphrasing words of community elder, male)

Alongside, these climate and social changes are the increases in frequency of shipping to the nearby mine. Participants have observed fewer seals and beluga whales in the Chesterfield Inlet harbour since shipping increased from three or four ships annually to 30-40 ships to supply the mine. As a result of the ship traffic, according to study participants, hunting is more costly and hunters are less successful at it. Importantly, when hunters are harvesting fewer marine mammals, they are unable to share as much within the community. This is an important concern for participants as it will disrupt the health of the community.

Oh, I share it to quite a few people. The stuff I don't really eat I give away to people, like to the elder. I usually do that every year. People who don't have like hunting stuff I give them meat and whatever I can. [...] Sometimes I go through Hamlet because sometimes they pay people to go hunting but when that don't go around I still give for free. I give a lot of meat for free... But like in the spring when it gets hard to catch, like caribou, I kinda get stingy. (Current hunter, male)

[When hunters harvest a lot of country food then there's] enough for other people too, I could share them [harvested country food]. But if it's only few [animals harvested] then ...I just take it [for myself]. (Casimir A.M. Kriterdluk, community elder, male)

\section{Discussion}

It is important to acknowledge that community-based research is a time-consuming method for community members and to avoid engaging with communities experiencing research fatigue. Because Chesterfield Inlet has not collaborated on community-based research in the past, an important part of the research process was to begin to build research capacity and establish expectations between the researcher and the community. Community members were engaged throughout the research process, teaching the lead author about life in the Arctic and Inuit culture. Their involvement in developing the research questions and discussing the results was crucial to the success of this study and represented a significant investment of time for many members. Given all of the informal conversations, additional people present during interviews and the confidence expressed by community members in the elders' in-depth knowledge, it was agreed by Newell and the Community Partner that sufficient participation was reached. This also demonstrates the broader community engagement in this research project, which led the Community Partner to insist that the community be acknowledged as a co-author rather than himself. This was also agreed upon by the mayor, who, along with the Community Partner, gave feedback on manuscript drafts. Including the community of Chesterfield Inlet as authors in this paper is an important step in ensuring that research is respectful and empowering, using the community-based approach.

\section{Linking food security, cultural continuity and community health and well-being}

While the importance of country food for Inuit communities is not a new research concept, this study makes clear the ways Inuit in Chesterfield Inlet perceive that sharing country food connects food security, cultural continuity and community health and well-being. This allows community members to voice their concern about how changes are impacting community and marine mammal health. During community consultations and interviews, country food harvesting and sharing emerged as the connection among individual food security, cultural continuity and community health and well-being for community members in Chesterfield Inlet. Sharing country food, especially freshly harvested large game (e.g., walrus and beluga), helps people to continue their traditional Inuit culture today. This sharing also improves the food security of community members who are unable to harvest country food themselves, such as elders. While sharing country food increases the food security of individual community members, it also improves the health and well-being of the community overall through building stronger relationships between people.

Community members described how sharing, rather than selling, country food not only promotes individual food security but also fosters a positive social environment and promotes healthy connections among community members. Within Chesterfield Inlet, sharing country food promotes a sense of community well-being, which participants described as a feeling of taking care of one another, particularly those unable to go out on the land or struggling financially, and a feeling of being welcome in the community. This feeling is a key factor in the health and well-being of the community as a whole. Therefore, 
for hunters, sharing country food is part of ensuring the well-being of the overall community. In Chesterfield Inlet, this sharing went beyond the family or social network identified in other studies (Lardeau et al. 2011; Collings et al. 2015). Through the Nunavut Community Hunt Program, funding was given to hunters to harvest specifically for community members who had requested country food. Recipients of country food acquired in this way were not required to pay for it. Many participants explained how they could ask on the local radio station, which broadcasted announcement of community events within the settlement, if they wanted country food, moving beyond their family or social networks while doing so.

\section{How change will impact community health and well-being}

Understanding how Inuit perceive community health and well-being as being connected-through country food sharing-to food security and cultural continuity is a baseline for predicting how changes will impact the community. As environmental and social changes impede hunters' harvesting of country food, this will diminish their ability to share within the community, negatively impacting overall health and well-being in Chesterfield Inlet. This has become a major concern for community members as climate change allows for more shipping, which will exacerbate the impacts they are already experiencing. The pairing of Western scientific methods and Inuit traditional knowledge demonstrated by this study has produced evidence that community members can use to voice their concern about how human health is being undermined by the changing environmental conditions that animals are experiencing. Community members have already presented findings from this study to regional organizations, the local mining company and, in 2020, the Northern Lights Trade Show to advocate for changes (Lightfoot 2020).

\section{Limitations of community-based research}

It is important to recognize that while community-based research is a culturally appropriate and ethical research approach for Arctic Inuit communities, the results are specific to the collaborating community. In this case, participants in Chesterfield Inlet recognize that sharing of country food is a practice that may vary across communities in Nunavut, despite a history of sharing across the region. Decision-makers need to take into consideration the regional differences when creating policy based on this research. While supporting community harvesting practices in Chesterfield Inlet would benefit community health and well-being, another community that has different sharing practices may not be impacted in the same way. Nonetheless, what this study shows is the importance of understanding the impact on small communities of even subtle changes in practices and the influence of external policy on traditional lifeways.

\section{Policy implications}

With varying degrees of success, other policies address food insecurity in Nunavut and the wider Canadian Arctic region (Feeding Nunavut 2017; Government of Canada 2018). As participants described, the health of Inuit is impacted by their ability to travel on the land and continue their traditional practices of harvesting and sharing country food. Therefore, policy that supports food security is not always what Westerners conventionally conceptualize as providing access to affordable foods.

Participants were of the opinion that food policies should not focus solely on market food costs. The Nutrition North programme is an example of such a policy and that has been found problematic (Samson \& Pretty 2006; Burnett et al. 2015; Galloway 2017; Kenny et al. 2018). Studies of the nutrition transition have revealed the negative impacts of market food on the health of Indigenous peoples (Kuhnlein et al. 2004; Counil et al. 2008; Egeland, Johnson-Down et al. 2011). Although storebought food is not a preference for many of the participants in Chesterfield Inlet, participants did acknowledge the importance of having market foods for preparing country foods, for example, caribou stew. Policies aimed at reducing food insecurity in Nunavut need to consider market food alongside country food accessibility. This study also suggests that multiple policies are needed across sectors to address food insecurity in Nunavut.

As community members explained, current hunting practices involve a snowmobile, boat or all-terrain vehicle with associated fuel, guns, ammunition, fishing rods and survival gear. The cost of many of these items is elevated by the cost of transporting them to Chesterfield Inlet, which is remote. The Harvesting Equipment Program, which is part of the Nunavut Harvesters Support Program, provides important funds to meet these needs. Additionally, through the Nunavut Harvesters Support Program, the Government of Nunavut financially compensates hunters for time and equipment used to harvest country food that is subsequently shared with other community members. These programmes are constantly under review. Continuing and increasing the funding for such programmes in Nunavut is important to not only sustaining food security but also continuing cultural practices that are important to Inuit. 
When creating policy related to country food, it is important to balance the risks associated with an activity-such as safety concerns while travelling on sea ice and contaminants present in country food-against its benefits, such as cultural continuity and vitamins and minerals. An important part of balancing the risks and benefits is ensuring that community members are involved in the decision-making process-that their voices, values and knowledge are not only present at the table but are respected and considered equal to other participants in the decision-making process. Community members expressed frustration about decisions that had been made without taking their local knowledge or input into serious consideration. Decisions regarding policy aimed at addressing food insecurity in Nunavut and across the Arctic must consider local knowledge and involve local stakeholders to ensure the development of effective solutions that are culturally sensitive.

\section{Conclusions}

This study has shown how Inuit in Chesterfield Inlet perceive harvesting and sharing country food as connecting community health and well-being, food security and cultural continuity. Community members in Chesterfield Inlet are still harvesting and sharing country food to improve their own and other community members' food security, while continuing to practice their traditional Inuit culture. This paper establishes how changes in country food access and availability, due to factors such as climate changes and increased shipping, will impact not only the individual harvester's health and well-being but also the entire community. Policies need to support harvesting and consumption of country food to promote individual and community health and wellbeing in Chesterfield Inlet.

The use of community-based research methods in this study ensured that Chesterfield Inlet's interests were represented and improved the quality of the research results. Various community members participated throughout the research project through formal data collection and informal conversations that guided the process throughout. This approach has generated an interest in future research in the community, in which members can collaborate and learn more about issues that are key to surviving_-and thriving_in the Arctic.

\section{Acknowledgements}

The authors would like to thank the many community members who were involved in the community consultations and interviews, including Harry Aggark, Lena Autut, Louie Autut, Valerie Ipkarnerk, Eli Kimmaliardjuk,
Jimmy Krako, Elizabeth Kreelak, Casimir A.M. Kriterdluk, Theresa Kukkiak, Leo Mimialik, Simionie Sammurtok, Eva Tanuyak, Andre Tautu, Elizabeth Tautu and Larry Tautu, as well as members of the Chesterfield Inlet Hamlet Council and the Aqigiq Hunters and Trappers Organization. Special thanks to David Kattegatsiak for his collaboration throughout the research process and to the Chesterfield Inlet Hamlet Council and the Aqigiq Hunters and Trappers Organization for their support throughout this research. Sincerest thanks to Sarah Dickson, Corinne Schuster-Wallace, Lynne Kennedy, Sonia Wesche and the journal reviewers for their feedback on manuscript drafts.

\section{Disclosure statement}

The authors report no conflict of interest.

\section{Funding}

This research was financially supported by the Social Sciences and Humanities Research Council of Canada's Ocean Canada Partnership Grant and the Northern Scientific Training Program.

\section{References}

Auger M.D. 2016. Cultural continuity as a determinant of Indigenous peoples' health: a metasynthesis of qualitative research in Canada and the United States. International Indigenous Policy Journal 7, article no. 3, doi: 10.18584/iipj.2016.7.4.3.

Berrang-Ford L., Ford J.D. \& Paterson J. 2011 . Are we adapting to climate change? Global Environmental Change 21, 25-33, doi: 10.1016/j.gloenvcha.2010.09.012.

Burnett K., Skinner K. \& LeBlanc J. 2015. From food mail to nutrition north Canada: reconsidering federal food subsidy programs for northern Ontario. Canadian Food Studies/La Revue Canadienne des Études sur l'Alimentation 2, 141-156, doi: 10.15353/cfs-rcea.v2il.62.

CBC News 2015. Shipping route affecting marine mammals: Chesterfield Inlet Mayor. Accessed on the internet at https://www.cbc.ca/news/canada/north/shipping-route-affecting-marine-mammals-chesterfield-inlet-mayor-1.2937831 on 30 September 2020.

Chan H.M., Fediuk K., Hamilton S., Rostas L., Caughey A., Kuhnlein H., Egeland G. \& Loring E. 2006. Food security in Nunavut, Canada: barriers and recommendations. International Journal of Circumpolar Health 65, 416-431, doi: 10.3402/ijch.v65i5.18132.

Chandler M.J. \& Lalonde C.E. 1998. Cultural continuity as a hedge against suicide in Canada's First Nations. Transcultural Psychiatry 35, 191-219, doi: $10.1177 / 136346159803500202$

CIHR (Canadian Institutes of Health Research, Natural Sciences and Engineering Research Council of Canada and 
Social Sciences and Humanities Research Council of Canada) 2010. Tri-council policy statement. Ethical conduct for research involving humans. Ottawa: Interagency Secretariat on Research Ethics.

Collings P., Marten M.G., Pearce T. \& Young A.G. 2015. Country food sharing networks, household structure, and implications for understanding food insecurity in Arctic Canada. Ecology of Food and Nutrition 55, 30-49, doi: 10.1080/03670244.2015.1072812.

Cormier S. 2016. Enhancing Indigenous food security in the Arctic: through law, policy, and the Arctic Council. Master's thesis. Faculty of Law, University of Lapland, Rovaniemi, Finland.

Counil É., Dewailly É., Bjerregaard P. \& Julien P. 2008. Transpolar-fat: all Inuit are not equal. The British Journal of Nutrition 100, 703-706, doi: 10.1017/S0007114508925447.

Cunsolo Willox A. 2012. Climate change as the work of mourning. Ethics and the Environment 17, 137-164, doi: 10.2979/ethicsenviro.17.2.137.

Cunsolo Willox A., Stephenson E., Allen J., Bourque F., Drossos A., Elgarøy S., Kral M.J., Mauro I., Moses J., Pearce T., MacDonald J.P. \& Wexler L. 2014. Examining relationships between climate change and mental health in the Circumpolar North. Regional Environmental Change 15, 169-182, doi: 10.1007/s10113-014-0630-z.

Davidson A.D., Boyer A.G., Kim H., Pompa-Mansilla S., Hamilton M.J., Costa D.P., Ceballos G. \& Brown J.H. 2012. Drivers and hotspots of extinction risk in marine mammals. Proceedings of the National Academy of Sciences of the United States of America 109, 3395-3400, doi: 10.1073/ pnas. 1121469109

Dept. of Health 2020. Nunavut food guide. Iqaluit, NU: Government of Nunavut. Accessed on the internet at https:// livehealthy.gov.nu.ca/en/healthy-eating/nunavut-foodguide on 21 September 2020.

Donaldson S.G., Van Oostdam J., Tikhonov C., Feeley M., Armstrong B., Ayotte P., Boucher O., Bowers W., Chan L., Dallaire F., Dallaire R., Dewailly E., Edwards J., Egeland G.M., Fontaine J., Furgal C., Leech T., Loring E., Muckle G., Nancarrow T., Pereg D., Plusquellec P, Potyrala M., Receveur O. \& Shearer R.G. 2010. Environmental contaminants and human health in the Canadian Arctic. Science of the Total Environment 408, 5165-5234, doi: 10.1016/j.scitotenv.2010.04.059.

Downing A. \& Cuerrier A. 2011. A synthesis of the impacts of climate change on the First Nations and Inuit of Canada. Indian Journal of Traditional Knowledge 10, 57-70.

Egeland G.M., Johnson-Down L., Cao Z.R., Sheikh N. \& Weiler H. 2011. Food insecurity and nutrition transition combine to affect nutrient intakes in Canadian Arctic communities. The Journal of Nutrition 141, 1746-1753, doi: 10.3945/jn.111.139006.

Egeland G.M., Williamson-Bathory L., Johnson-Down L. \& Sobol I. 2011. Traditional food and monetary access to market-food: correlates of food insecurity among Inuit preschoolers. International Journal of Circumpolar Health 70, 373-383, doi: 10.3402/ijch.v70i4.17836.

EP (Expert Panel on the State of Knowledge of Food Security in Northern Canada) 2014. Aboriginal food security in northern Canada: an assessment of the state of knowledge. Ottawa: Council of Canadian Academies.
Feeding Nunavut 2017. Update: Feeding Nunavut Harvester Support Program. Accessed on the internet at https:// Www.feedingnunavut.com/feeding-nunavut-harvester-support-program/ on 28 January 2019.

Ford J.D. \& Beaumier M. 2011. Feeding the family during times of stress: experience and determinants of food insecurity in an Inuit community. Geographical Journal 177, 44-61, doi: 10.1111/j.1475-4959.2010.00374.x.

Ford J.D., Cunsolo Willox A., Chatwood S., Furgal C., Harper S., Mauro I. \& Pearce T. 2014. Adapting to the effects of climate change on Inuit health. American Journal of Public Health 104 (Suppl. 3), e9-e17, doi: 10.2105/ AJPH.2013.301724.

Ford J.D., MacDonald J.P., Huet C., Statham S. \& MacRury A. 2016. Food policy in the Canadian North: is there a role for country food markets? Social Science and Medicine 152, 35-40, doi: 10.1016/j.socscimed.2016.01.034.

Ford J.D., Pearce T., Duerden F., Furgal C. \& Smit B. 2010. Climate change policy responses for Canada's Inuit population: the importance of and opportunities for adaptation. Global Environmental Change 20, 177-191, doi: 10.1016/j. gloenvcha.2009.10.008.

Ford J.D., Pearce T., Smit B., Wandel J., Allurut M., Shappa K., Ittusujurat H. \& Qrunnut K. 2007. Reducing vulnerability to climate change in the Arctic: the case of Nunavut, Canada. Arctic 60, 150-166, doi: 10.2307/40513131.

Gale N.K., Heath, G., Cameron E., Rashid S. \& Redwood S. 2013. Using the framework method for the analysis of qualitative data in multi-disciplinary health research. BMC Medical Research Methodology 13, article no. 117, doi: 10.1186/1471-2288-13-117.

Galloway T. 2017. Canada's northern food subsidy Nutrition North Canada: a comprehensive program evaluation. International Journal of Circumpolar Health 76, article no. 1279451, doi: 10.1080/22423982.2017.1279451.

Gmelch L., Hintelmann H., Hickie B., Kienberger H., Stern G. \& Rychlik M. 2017. Risk-benefit assessment of monomethylmercury and omega-3 fatty acid intake for ringed seal consumption with particular emphasis on vulnerable populations in the western Canadian Arctic. Frontiers in Nutrition 4, article no. 30, doi: 10.3389/ fnut.2017.00030.

Government of Canada 2018. How Nutrition North Canada works. Accessed on the internet at https://www.nutritionnorthcanada.gc.ca/eng/1415538638170/1415538670874 on 28 January 2019.

Guo Y., Berrang-Ford L., Ford J.D., Lardeau M.-P., Edge V., Patterson K. \& Harper S.L. 2015. Seasonal prevalence and determinants of food insecurity in Iqaluit, Nunavut. International Journal of Circumpolar Health 74, article no. 27284, doi: 10.3402/ijch.v74.27284.

Hackett C., Feeny D. \& Tompa E. 2016. Canada's residential school system: measuring the intergenerational impact of familial attendance on health and mental health outcomes. Journal of Epidemiology and Community Health 70, 1096-1105, doi: 10.1136/jech-2016-207380.

Harder M.T. \& Wenzel G.W. 2012. Inuit subsistence, social economy and food security in Clyde River, Nunavut. Arctic 65, 305-318, doi: 10.14430/arctic4218. 
Kendrick A. 2013. Canadian Inuit sustainable use and management of Arctic species. International Journal of Environmental Studies 70, 414-428, doi: 10.1080/00207233.2013.801176.

Kenny T.A., Fillion M., MacLean J., Wesche S.D. \& Chan H.M. 2018. Calories are cheap, nutrients are expensivethe challenge of healthy living in Arctic communities. Food Policy 80, 39-54, doi: 10.1016/j.foodpol.2018.08.006.

King M. 2009. An overall approach to health care for Indigenous peoples. Pediatric Clinics of North America 56, 1239-1242, doi: 10.1016/j.pcl.2009.09.005.

Kirmayer L.J., Brass G.M. \& Tait C.L. 2000. The mental health of aboriginal peoples: transformations of identity and community. Canadian Journal of Psychiatry 45, 607616, doi: 10.2307/2077147.

Kral M.J. \& Idlout L. 2012. It's all in the family: wellbeing among Inuit in Arctic Canada. In H. Selin \& G. Davey (eds.): Happiness across cultures: views of happiness and quality of life in non-Western cultures. Pp. 271-292. Heidelberg: Springer Science \& Business Media.

Kuhnlein H.V., Receveur O., Soueida R. \& Egeland G.M. 2004. Arctic Indigenous peoples experience the nutrition transition with changing dietary patterns and obesity. Journal of Nutrition 134, 1447-1453, doi: 10.1093/jn/134.6.1447.

La Placa V., McNaught A. \& Knight A. 2013. Discourse on wellbeing in research and practice. International Journal of Wellbeing 3, 116-125, doi: 10.5502/ijw.v3il.7.

Lardeau M.-P., Healey G., Ford J.D., Lardea M.P., Heale G. $\&$ Ford J. 2011. The use of photovoice to document and characterize the food security of users of community food programs in Iqaluit, Nunavut. Rural and Remote Health 11, article no. 1680.

Lightfoot P. 2020. Chesterfield Inlet mayor pitches deep-sea port to ease effects of increased shipping. Nunatsiaq News, 11 February.

Masson-Delmotte V., Zhai P., Pörtner H.-O., Roberts D., Skea J., Shukla P.R., Pirani A., Moufouma-Okia W., Péan C., Pidcock R., Connors S., Matthews J.B.R., Chen Y., Zhou X., Gomis M.I., Lonnoy E., Maycock T., Tignor M. \& Waterfield T. (eds.) 2018. Global warming of $1.5^{\circ} \mathrm{C}$. An IPCC special report on the impacts of global warming. Summary for policymakers. Geneva: Intergovernmental Panel on Climate Change.

Nancarrow T.L. \& Chan H.M. 2010. Observations of environmental changes and potential dietary impacts in two communities in Nunavut, Canada. Rural and Remote Health 10, article no. 1370.

Newell S.L. 2017. Chesterfield Inlet community report-impacts of shipping. Unpublished report prepared for the Chesterfield Inlet community.

Newell S.L. 2018. Social, cultural, and ecological systems' influence on community health and wellbeing. $\mathrm{PhD}$ dissertation. McMaster University, Hamilton, ON, Canada.

Newell S.L., Dion M.L. \& Doubleday N.C. 2019. Cultural continuity and Inuit health in Arctic Canada. Journal of Epidemiology and Community Health 74, 64-70, doi: 10.1136/ jech-2018-211856.

Oster R.T., Grier A., Lightning R., Mayan M.J. \& Toth E.L. 2014. Cultural continuity, traditional Indigenous language, and diabetes in Alberta First Nations: a mixed methods study. International Journal for Equity in Health 13, article no. 92, doi: 10.1186/s12939-014-0092-4.

Paci C.D.J., Dickson C., Nickels S., Chan L. \& Furgal C. 2004. Food security of northern Indigenous peoples in a time of uncertainty. Presented at the Third Northern Research Forum Open Meeting. The Resilient North: Human Responses to Global change, 15-18 September, Yellowknife, NT.

Parlee B. \& Furgal C. 2012. Well-being and environmental change in the Arctic: a synthesis of selected research from Canada's International Polar Year program. Climatic Change 115, 13-34, doi: 10.1007/s10584-012-0588-0.

Pinstrup-Andersen P. 2009. Food security: definition and measurement. Food Security 1, 5-7, doi: 10.1007/ s12571-008-0002-y.

Reading C.L. \& Wein F. 2009. Health inequalities and social determinants of aboriginal peoples' health. Prince George, BC: National Collaborating Centre for Aboriginal Health.

Ready E. 2016. Challenges in the assessment of Inuit food security. Arctic 69, 266-280, doi: 10.14430/arctic4579.

Ready E. 2018a. Who, being loved, is poor? Poverty, marriage, and changing family structures in the Canadian arctic. Human Organization 77, 122-134, doi: 10.17730/0018-7259-77.2.122.

Ready E. 2018b. Sharing-based social capital associated with harvest production and wealth in the Canadian Arctic. PLoS One 13, e0193759, doi: 10.1371/journal.pone.0193759.

Rosol R., Powell-Hellyer S. \& Chan H.M. 2016. Impacts of decline harvest of country food on nutrient intake among Inuit in Arctic Canada: impact of climate change and possible adaptation plan. International Journal of Circumpolar Health 75, article no. 31127, doi: 10.3402/ijch.v75.31127.

Samson C. \& Pretty J. 2006. Environmental and health benefits of hunting lifestyles and diets for the Innu of Labrador. Food Policy 31, 528-553, doi: 10.1016/j.foodpol.2006.02.001.

Searles E. 2016. To sell or not to sell: country food markets and Inuit identity in Nunavut. Food and Foodways 24, 194-212, doi: 10.1080/07409710.2016.1210899.

Statistics Canada 2016. Census profile, 2016 census. Chesterfield Inlet, Hamlet (Census subdivision), Nunavut. Accessed on the internet at https://wwwl2.statcan. gc.ca/census-recensement/2016/dp-pd/prof/details/ page.cfm? Lang=E\&Geol $=$ CSD\&Code $1=6205019 \&$ Geo2 $=$ PR\& Code $2=62 \&$ SearchText $=$ Chesterfield $\% 20$ Inlet $\delta$ Search Type $=$ B egins $\delta$ Search $P R=01 \& \mathrm{~B} 1=\mathrm{All} \&$ GeoLevel $=$ PR\&GeoCode $=62050198 \mathrm{TABID}=1$ \& type $=0$ on 27 November 2017.

Thompson S. 2005. Sustainability and vulnerability: aboriginal Arctic food security in a toxic world. In F. Berkes et al. (eds.): Breaking ice: renewable resource and ocean management in the Canadian North. Pp. 47-69. Calgary, AB: University of Calgary Press.

TRC (Truth and Reconciliation Commission of Canada) 2015. Honouring the truth, reconciling for the future. Summary of the final report of the Truth and Reconciliation Commission of Canada. Winnipeg, MB: Truth and Reconciliation Commission of Canada.

Wakegijig J., Osborne G., Statham S. \& Issaluk M.D. 2013. Collaborating toward improving food security in Nunavut. International Journal of Circumpolar Health 72, article no. 21201, doi: 10.3402/ijch.v72i0.21201. 
Weihs F., Higgins R. \& Boult D. 1993. A review and assessment of the economic utilisation and potential of country food in the northern economy. Ottawa: Royal Commission on Aboriginal People.

Wesche S.D. \& Chan H.M. 2010. Adapting to the impacts of climate change on food security among inuit in the western Canadian Arctic. EcoHealth 7, 361-373, doi: 10.1007/ s10393-010-0344-8.
White D.M., Gerlach S.C., Loring P., Tidwell A.C. \& Chambers M.C. 2007. Food and water security in a changing Arctic climate. Environmental Research Letters 2, article no. 045018, doi: 10.1088/1748-9326/2/4/045018.

Wiseman J. \& Brasher K. 2008. Community wellbeing in an unwell world: trends, challenges, and possibilities. Journal of Public Health Policy 29, 353-366, doi: 10.1057/ jphp.2008.16. 